\title{
Position Forward Kinematics of 6-D0F Robotic Arm
}

\author{
Štefan Ondočko * , Tomáš Stejskal, Jozef Svetlík, Lukáš Hrivniak, Michal Šašala, Adam Žilinský \\ Technical University, Faculty of Mechanical Engineering, Department of Manufacturing Machinery, Letná 9, 04200 Košice, Slovakia
}

\begin{abstract}
The paper describes the construction and verification of a kinematic model of a robotic arm position, which should be composed of special modules (URM). The concept of modularity plays a fairly important role here, as it is possible to assemble from individual modules machines with different movement options and several degrees of freedom. The degrees of freedom of the arm are facilitated by six rotating links, which are, thank to those modules, unlimited. The actual implementation of the robotic arm's kinematic model into the software environment occurred in two environments. In order to check the correctness of the calculation of the individual parts of the kinematic structure's position in space, two different models were intentionally created. A mathematical model in Matlab - Simulink and a mechanical model built in the Matlab - Simscape environment.
\end{abstract}

Keywords: matlab; kinematics; manufacturing technology; modular structures; coordinate transformation.

\section{Introduction}

The system modularity has specific features that convey many benefits. Reconfigurability and extensibility are the two of them mentioned most often. They are deployed in various areas of production. Whether in the products themselves or in the production systems [1-5]. This modular philosophy is used in the described device, and its whole development is well described in $[1,2,6]$. The main idea of the solution proposed is the possibility to assemble from one URM (Unlimited Rotational Module) module type the machines with different movement options and several degrees of freedom. The URM module has unlimited rotation and is a basic element for assembling kinematic structures. All this is done with a view to ensure the widest possible range of workspace and operational safety, to prevent the kinematic structure's collision with itself. In course of the module development, its designers emphasized its autonomy, functional independence, size and weight reduction [7]. Each module has its own communication unit, power supply, contactless power transmission. The main use of the module is expected to be found in the construction of robotic and handling equipment. Subject to suitable modification, the modules can also be used in the construction of special-purpose manufacturing machines. Commonly addressed tasks [10] in the design of a robotic manipulator are in particular the following ones:

- Forward, direct and inverse kinematics, or also a forward and inverse geometric model (relationship between position vectors in the Cartesian coordinate system and joint coordinate vectors, i.e. especially the position of the end effector and the position of the actuator)

- Forward, direct and inverse kinematics model, but concerning already the relationships between velocities, acceleration or higher time derivatives of position vectors and joint coordinate vectors

- Identification and addressing of singular positions as far as possible, as they cause a reduction in the manipulator mobility, numerical problems in the inverse calculation. Small changes in position can cause large changes in the 

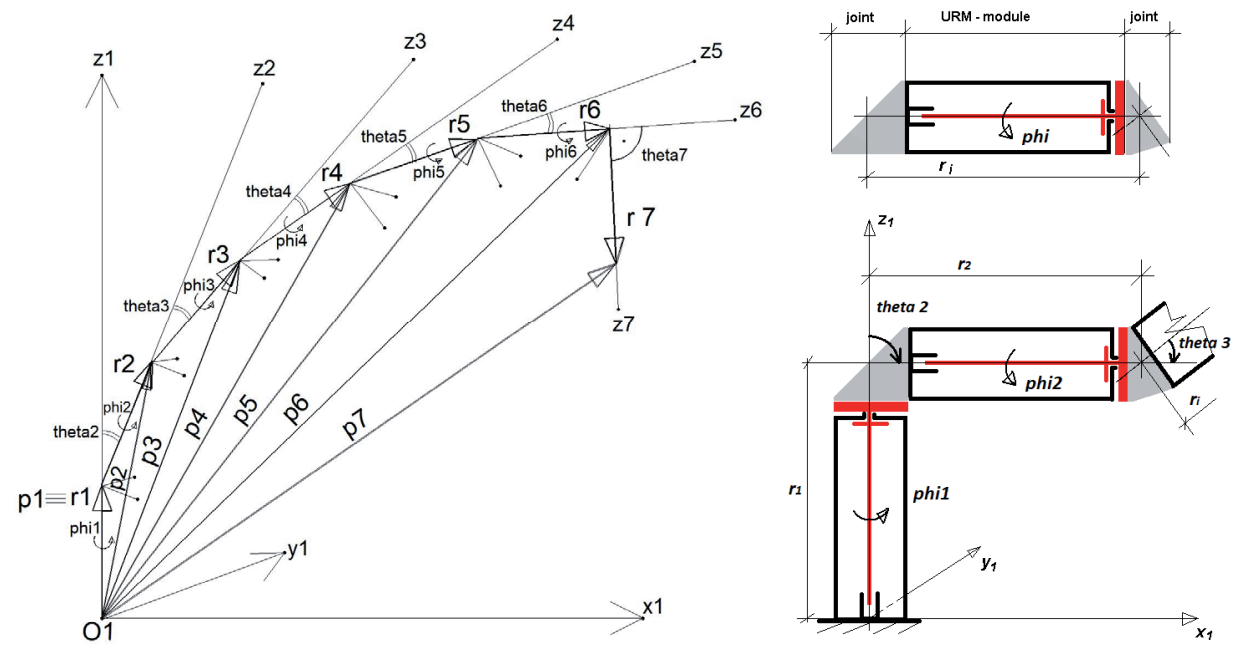

Figure 1: Robotic arm composed of modules.

joints and, thus, a great deal of effort required of the actuators. Particularly annoying are the singularities found in the manipulator's workspace

- Imaging, examination of the manipulator's workspace, manipulator movement planning, control, taking into account the dynamics of the device in relation to the desired movement, etc. [8, 9], etc.

Despite many sophisticated methods, software support, and different approaches used, problems in practice crop up. Not every such problem can always be solved easily and satisfactorily. In this paper, the forward kinematics of the position (for example [11-14]) of the robotic arm with 6 degrees of freedom is derived in principle that expects the use of the URM modules (relationship between position vectors in the Cartesian coordinate system and joint coordinate vectors). Two models were made intentionally. The mathematical one, where a model in the Matlab - Simulink environment was built based on the relationships of position vectors. In addition, the mechanical one, composed of simplified virtual bodies with predefined transformations (rotation in space, lengths), created in the Matlab - Simscape environment. The mechanical model was basically intended to confirm the accuracy of the calculation and to visualize the model. The task is to implement the relations [15] describing the robotic arm's position forward kinematics in Matlab - Simulink. These relations describe the position of points using position vectors $\boldsymbol{p}_{\mathrm{i}}$, [22, 23] where $i \in\langle 1$;7 $\rangle$ at individual segments $-\boldsymbol{r}_{\mathrm{i}}$ in the so-called serial kinematic structure. The reason for such relational implementation is to enable a numerical calculation of the position of a point, at which effector may be found $[18,24,25,26]$ to be carried out. The point position (given by the values of the position vector components) $\left[\boldsymbol{p}_{\mathrm{xi}}, \boldsymbol{p}_{\mathrm{yi}}, \boldsymbol{p}_{\mathrm{zi}}\right]$ will thus be defined by the function $\varphi_{i}, \boldsymbol{\vartheta}_{\mathrm{i}}$ and the segment size - $\left|\boldsymbol{r}_{\mathrm{i}}\right|$ of the structure at hand; $\boldsymbol{p}_{\mathrm{i}}=f\left(\boldsymbol{\varphi}_{\mathrm{i}}, \boldsymbol{\vartheta}_{\mathrm{i}}, \boldsymbol{r}_{\mathrm{i}}\right)$. The arm's base is an autonomous URM module $[18,19]$ in the shape of a cylinder (Figure 1). These modules have one degree of freedom, namely the rotational one. Rotation occurs around the module's main axis and it is not limited to the range 0-360 degree. Continuous rotation may take place unhindered in either of the two directions of rotation. In this plane, we expect the modules and the joints to be perfectly rigid bodies.

Transformation through more (Cartesian) coordinate systems in three-dimensional Euclidean coordinates $[19,20]$. Segment rotation around the zi axis is defined by a rotation matrix $\boldsymbol{R}_{\mathrm{zi}}\left(\varphi_{\mathrm{i}}\right)[18,19]$. Segment rotation around the $y_{\mathrm{i}}$ axis is defined by a rotation matrix $\boldsymbol{R}_{\mathrm{yi}}\left(\vartheta_{\mathrm{i}}\right)$. Thus, the following can be entered for $\boldsymbol{R}_{\mathrm{zi}}\left(\varphi_{\mathrm{i}}\right)$

$R_{z i}\left(\phi_{i}\right)=\left[\begin{array}{ccc}\cos \left(\phi_{i}\right) & -\sin \left(\phi_{i}\right) & 0 \\ \sin \left(\phi_{i}\right) & \cos \left(\phi_{i}\right) & 0 \\ 0 & 0 & 1\end{array}\right]$

And the entry below for $\boldsymbol{R}_{\mathrm{yi}}\left(\boldsymbol{\vartheta}_{\mathrm{i}}\right)$

$R_{y i}\left(\vartheta_{i}\right)=\left[\begin{array}{ccc}\cos \left(\vartheta_{i}\right) & 0 & \sin \left(\vartheta_{i}\right) \\ 0 & 1 & 0 \\ -\sin \left(\vartheta_{i}\right) & 0 & \cos \left(\vartheta_{i}\right)\end{array}\right]$ 
The following applies for the position vector $\boldsymbol{p}_{1}$ according to (Figure 1)

$p_{1}=R_{z 1}\left(\phi_{1}\right) \times r_{1}$

The following applies for the position vectors $\boldsymbol{p}_{2}, \boldsymbol{p}_{3}$, $\boldsymbol{p}_{4}$, to $\boldsymbol{p}_{\mathrm{i}}$ according to (Figure 1)

$$
\begin{aligned}
p_{2}= & p_{1}+R_{z 1}\left(\phi_{1}\right) \times R_{y 2}\left(\vartheta_{2}\right) \times R_{z 2}\left(\phi_{2}\right) \times r_{2} \\
p_{3}= & p_{2}+R_{z 1}\left(\phi_{1}\right) \times R_{y 2}\left(\vartheta_{2}\right) \times R_{z 2}\left(\phi_{2}\right) \times R_{y 3}\left(\vartheta_{3}\right) \times \\
& \times R_{z 3}\left(\phi_{3}\right) \times r_{3} \\
p_{4} & =p_{3}+R_{z 1}\left(\phi_{1}\right) \times R_{y 2}\left(\vartheta_{2}\right) \times R_{z 2}\left(\phi_{2}\right) \times \\
& \times R_{y 3}\left(\vartheta_{3}\right) \times R_{z 3}\left(\phi_{3}\right) \times R_{y 4}\left(\vartheta_{4}\right) \times R_{z 4}\left(\phi_{4}\right) \times r_{4}
\end{aligned}
$$

General formula for the position vector $\boldsymbol{p}_{\mathrm{i}+1}$

$$
\begin{aligned}
p_{i+1} & =R_{z 1}\left(\phi_{1}\right) \times \\
& \times\left[r_{1}+\sum_{k=1}^{i}\left[\prod_{j=1}^{k}\left(R_{y(j+1)}\left(\vartheta_{j+1}\right) \times R_{z(j+1)}\left(\phi_{j+1}\right)\right)\right] \times r_{k+1}\right]
\end{aligned}
$$

Alternatively a transformation in homogenous coordinates, where the Euclidean space $\boldsymbol{E}^{3}[19,20]$ is complemented with points at infinity. Provided a point at infinity exists, the position vector coordinates for a given point will be $\left[\boldsymbol{p}_{\mathrm{xi}}, \boldsymbol{p}_{\mathrm{yi}}, \boldsymbol{p}_{\mathrm{zi}}\right.$, 1], and should it not exist, they will be $\left[\boldsymbol{p}_{\mathrm{xi}}, \boldsymbol{p}_{\mathrm{yi}}, \boldsymbol{p}_{\mathrm{zi}}\right.$, $0]$. Unlike the Rotation matrix, the Transformation matrix defines simultaneously both the body's rotation and translation in space. Its importance is shown in the adjusted relations (15), (19). Thus, the segment rotation around the $z_{\mathrm{i}}$ axis is then defined by the transformation matrix $\boldsymbol{T}_{\mathrm{zi}}\left(\varphi_{\mathrm{i}}\right)[18,19]$. Segment rotation around the yi axis is defined by the transformation matrix $\boldsymbol{T}_{\mathrm{yi}}\left(\boldsymbol{\vartheta}_{\mathrm{i}}\right)$. Thus, we can make the following entry for $\boldsymbol{T}_{\mathrm{zi}}\left(\varphi_{\mathrm{i}}\right)$

$$
T_{z i}\left(\phi_{i}\right)=\left[\begin{array}{cccc}
\cos \left(\phi_{i}\right) & -\sin \left(\phi_{i}\right) & 0 & 0 \\
\sin \left(\phi_{i}\right) & \cos \left(\phi_{i}\right) & 0 & 0 \\
0 & 0 & 1 & 0 \\
0 & 0 & 0 & 1
\end{array}\right]
$$

And the entry below for $\boldsymbol{T}_{\mathrm{yi}}\left(\boldsymbol{\vartheta}_{\mathrm{i}}\right)$

$$
T_{y i}\left(\vartheta_{i}\right)=\left[\begin{array}{cccc}
\cos \left(\vartheta_{i}\right) & 0 & \sin \left(\vartheta_{i}\right) & 0 \\
0 & 1 & 0 & 0 \\
-\sin \left(\vartheta_{i}\right) & 0 & \cos \left(\vartheta_{i}\right) & 0 \\
0 & 0 & 0 & 1
\end{array}\right]
$$

In general, together with the displacement vector $\boldsymbol{t}$
$T_{y}(\vartheta, t)=\left[\begin{array}{cccc}\cos (\vartheta) & 0 & \sin (\vartheta) & t_{x} \\ 0 & 1 & 0 & t_{y} \\ -\sin (\vartheta) & 0 & \cos (\vartheta) & t_{z} \\ 0 & 0 & 0 & 1\end{array}\right]$

The following applies to the position vector $\boldsymbol{p}_{1}$ according to (Figure 1)

$p_{1}=T_{z 1}\left(\phi_{1}\right) \times r_{1}$

Then

$p_{1}=\left[\begin{array}{cccc}\cos \left(\phi_{i}\right) & -\sin \left(\phi_{i}\right) & 0 & 0 \\ \sin \left(\phi_{i}\right) & \cos \left(\phi_{i}\right) & 0 & 0 \\ 0 & 0 & 1 & 0 \\ 0 & 0 & 0 & 1\end{array}\right] \times\left[\begin{array}{c}r_{x 1} \\ r_{y 1} \\ r_{z 1} \\ 1\end{array}\right]$

The following applies to the position vector $\boldsymbol{p}_{2}$ according to (Figure 1)

$p_{2}=p_{1}+T_{z 1}\left(\phi_{1}\right) \times T_{y 2}\left(\vartheta_{2}\right) \times T_{z 2}\left(\phi_{2}\right) \times r_{2}$

or by inserting (11) into (13)

$p_{2}=T_{z 1}\left(\phi_{1}\right) \times r_{1}+T_{z 1}\left(\phi_{1}\right) \times T_{y 2}\left(\vartheta_{2}\right) \times T_{z 2}\left(\phi_{2}\right) \times r_{2}$

then

$p_{2}=T_{z 1}\left(\phi_{1}\right) \times\left(r_{1}+T_{y 2}\left(\vartheta_{2}\right) \times T_{z 2}\left(\phi_{2}\right) \times r_{2}\right)$

Since the $\boldsymbol{r}_{1}$ vector in this relation represents displacement, it can be implemented into the transformation matrix $\boldsymbol{T}_{\mathrm{y} 2}\left(\boldsymbol{\vartheta}_{2}, \boldsymbol{r}_{1}\right)$ according to the relation (10)

$T_{y 2}\left(\vartheta_{2}, r_{1}\right)=\left[\begin{array}{cccc}\cos \left(\vartheta_{2}\right) & 0 & \sin \left(\vartheta_{2}\right) & r_{x 1} \\ 0 & 1 & 0 & r_{y 1} \\ -\sin \left(\vartheta_{2}\right) & 0 & \cos \left(\vartheta_{2}\right) & r_{z 1} \\ 0 & 0 & 0 & 1\end{array}\right]$

which yields

$p_{2}=T_{z 1}\left(\phi_{1}\right) \times T_{y 2}\left(\vartheta_{2}, r_{1}\right) \times T_{z 2}\left(\phi_{2}\right) \times r_{2}$

The following applies to the position vector $\boldsymbol{p}_{3}$ according to (Figure 1)

$$
\begin{aligned}
p_{3} & =p_{2}+T_{z 1}\left(\phi_{1}\right) \times T_{y 2}\left(\vartheta_{2}, r_{1}\right) \times T_{z 2}\left(\phi_{2}\right) \times T_{y 3}\left(\vartheta_{3}\right) \times \\
& \times T_{z 3}\left(\phi_{3}\right) \times r_{3}
\end{aligned}
$$

or by inserting (17) into (18)

$$
\begin{aligned}
p_{3}= & T_{z 1}\left(\phi_{1}\right) \times T_{y 2}\left(\vartheta_{2}, r_{1}\right) \times T_{z 2}\left(\phi_{2}\right) \times \\
& \times\left(r_{2}+T_{y 3}\left(\vartheta_{3}\right) \times T_{z 3}\left(\phi_{3}\right) \times r_{3}\right)
\end{aligned}
$$

And since the $\boldsymbol{r}_{2}$ vector in this relation represents displacement, it can be implemented into the transformation matrix $\boldsymbol{T}_{\mathrm{y} 3}\left(\boldsymbol{\vartheta}_{3}, \boldsymbol{r}_{2}\right)$ according to the relation (10), which yields the following result 


$$
\begin{aligned}
p_{3}= & T_{z 1}\left(\phi_{1}\right) \times T_{y 2}\left(\vartheta_{2}, r_{1}\right) \times T_{z 2}\left(\phi_{2}\right) \times T_{y 3}\left(\vartheta_{3}, r_{2}\right) \times \\
& \times T_{z 3}\left(\phi_{3}\right) \times r_{3}
\end{aligned}
$$

The following applies to the position vector $\boldsymbol{p}_{4}$ according to (Figure 1)

$$
\begin{aligned}
p_{4}= & T_{z 1}\left(\phi_{1}\right) \times T_{y 2}\left(\vartheta_{2}, r_{1}\right) \times T_{z 2}\left(\phi_{2}\right) \times T_{y 3}\left(\vartheta_{3}, r_{2}\right) \times T_{z 3}\left(\phi_{3}\right) \times \\
& \times T_{y 4}\left(\vartheta_{4}, r_{3}\right) \times T_{z 4}\left(\phi_{4}\right) \times r_{4}
\end{aligned}
$$

General formula for the position vector $\boldsymbol{p}_{\mathrm{i}+1}$

$p_{i+1}=T_{z 1}\left(\phi_{1}\right) \times \prod_{j=1}^{i}\left(T_{y(j+1)}\left(\vartheta_{j+1}, r_{j}\right) \times T_{z(j+1)}\left(\phi_{j+1}\right)\right) \times r_{i+1}$

Table 1: Parameters inserted into the mathematical - (Figure 2) and mechanical - (Figure 3) model.

\section{Experimental Section}

In order to verify the calculation, each segment $\left|\boldsymbol{r}_{\mathrm{i}}\right|$, module orientation $\boldsymbol{\varphi}_{\mathrm{i}}$, passive joint orientation $\boldsymbol{\vartheta}_{\mathrm{i}}$ was of different size. (Table 1) lists the input parameters for the mathematical and the mechanical model.

Insertion of the parameters of (Table 1) into individual models yields the values of position vectors $\boldsymbol{p}_{\mathrm{i}}$.

\subsection{Mathematical model}

Based on the relations given in [15], (1) to (7), or, alternately, in the homogenous coordinates (8) to (22), an analytical model of the arm has been made in the basic Matlab - Simulink environment (Fig. 2).

\begin{tabular}{|l|c|l|l|l|l|l|l|l|}
\hline$\left|\boldsymbol{r}_{1}\right|[\mathrm{mm}]$ & 300 & absolute value of vector $\boldsymbol{r}_{1}$ & $\boldsymbol{\varphi}_{1}\left[^{\circ}\right]$ & 15 & rotation of vector $\boldsymbol{r}_{1}$ & $\boldsymbol{\vartheta}_{2}\left[{ }^{\circ}\right]$ & 15 & angle of vector $\boldsymbol{r}_{2}$ to axis $z_{1}$ \\
\hline$\left|\boldsymbol{r}_{2}\right|[\mathrm{mm}]$ & 250 & absolute value of vector $\boldsymbol{r}_{2}$ & $\boldsymbol{\varphi}_{2}\left[{ }^{\circ}\right]$ & 30 & rotation of vector $\boldsymbol{r}_{2}$ & $\boldsymbol{\vartheta}_{3}\left[{ }^{\circ}\right]$ & 30 & angle of vector $\boldsymbol{r}_{3}$ to axis $z_{2}$ \\
\hline$\left|\boldsymbol{r}_{3}\right|[\mathrm{mm}]$ & 200 & absolute value of vector $\boldsymbol{r}_{3}$ & $\boldsymbol{\varphi}_{3}\left[{ }^{\circ}\right]$ & 50 & rotation of vector $\boldsymbol{r}_{3}$ & $\boldsymbol{\vartheta}_{4}\left[{ }^{\circ}\right]$ & 45 & angle of vector $\boldsymbol{r}_{4}$ to axis $z_{3}$ \\
\hline$\left|\boldsymbol{r}_{4}\right|[\mathrm{mm}]$ & 150 & absolute value of vector $\boldsymbol{r}_{4}$ & $\boldsymbol{\varphi}_{4}\left[{ }^{\circ}\right]$ & 130 & rotation of vector $\boldsymbol{r}_{4}$ & $\boldsymbol{\vartheta}_{5}\left[{ }^{\circ}\right]$ & 60 & angle of vector $\boldsymbol{r}_{5}$ to axis $z_{4}$ \\
\hline$\left|\boldsymbol{r}_{5}\right|[\mathrm{mm}]$ & 100 & absolute value of vector $\boldsymbol{r}_{5}$ & $\boldsymbol{\varphi}_{5}\left[{ }^{\circ}\right]$ & 230 & rotation of vector $\boldsymbol{r}_{5}$ & $\boldsymbol{\vartheta}_{6}\left[{ }^{\circ}\right]$ & 75 & angle of vector $\boldsymbol{r}_{6}$ to axis $z_{5}$ \\
\hline$\left|\boldsymbol{r}_{6}\right|[\mathrm{mm}]$ & 50 & absolute value of vector $\boldsymbol{r}_{6}$ & $\boldsymbol{\varphi}_{6}\left[{ }^{\circ}\right]$ & 340 & rotation of vector $\boldsymbol{r}_{6}$ & $\boldsymbol{\vartheta}_{7}\left[{ }^{\circ}\right]$ & 90 & angle of vector $\boldsymbol{r}_{7}$ to axis $z_{6}($ effector) \\
\hline$\left|\boldsymbol{r}_{7}\right|[\mathrm{mm}]$ & 25 & absolute value of vector $\boldsymbol{r}_{7}$ & & & & & & \\
\hline
\end{tabular}

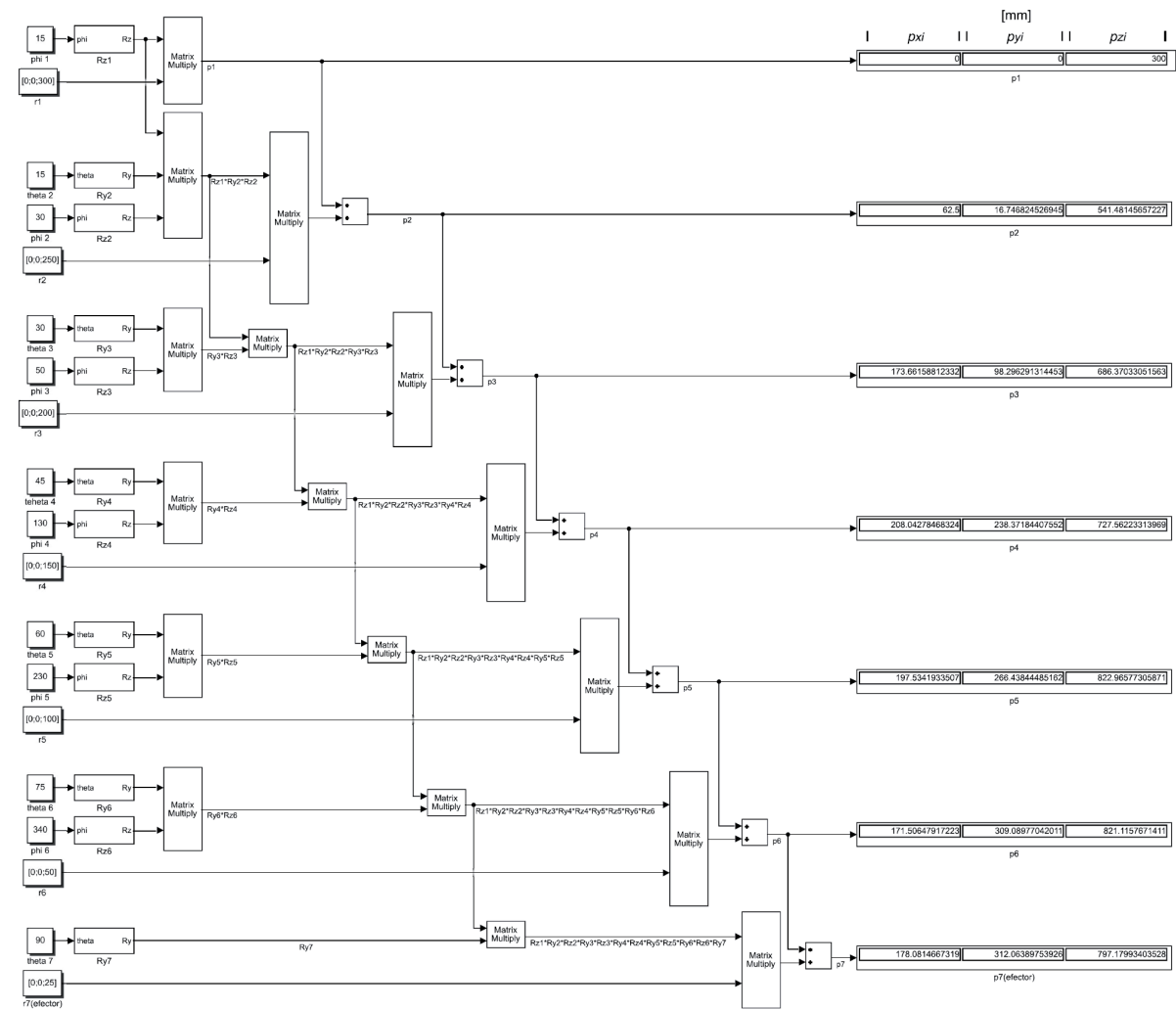

Figure 2: Mathematical model of the robotic arm. 


\subsection{Mechanical model}

Correctness of the mathematical model calculation has been checked in the Simscape/ Multibody environment, designated for modelling, physical systems simulation and for threedimensional mechanical devices. The mechanical model's construction draws on the principle shown in (Figure 1). Its execution is shown in (Figure 3). The base is a referential coordinate system $\left\{O_{1}, x_{1}, y_{1}, z_{1}\right\}$. Attached to the base is the first kinematic structure segment $-\left|\boldsymbol{r}_{1}\right|$. This is followed by transformation of the coordinates, or, to put it differently, by a rotation - $\left|\boldsymbol{r}_{1}\right|$ with the angle of $\varphi_{1}$ around the $z_{1}$ axis. This is no other than the rotation around the main robotic arm module's axis. This place belongs to the position vector $\boldsymbol{p}_{1}$. That is why a translational sensor is mounted to this place. Another transformation of coordinates comes next (segment rotate) - $\left|\boldsymbol{r}_{2}\right|$ by the angle of $\boldsymbol{\vartheta}_{2}$ around the $y_{2}$ axis. This rotation represents the passive joint itself, located between two segments $\left|\boldsymbol{r}_{1}\right|,\left|\boldsymbol{r}_{2}\right|$ of the kinematic structure. The entire structure is built in this manner, with places for position measurements, represented by the individual position vectors $\boldsymbol{p}_{\mathrm{i}}$

Values of the $\boldsymbol{p}_{\mathrm{xi}}, \quad \boldsymbol{p}_{\mathrm{yi}}, \quad \boldsymbol{p}_{\mathrm{zi}}$ position vectors 'components, derived from the calculation from the model - (Figure 2) and also from taking the model's measurements - (Figure 3) are listed in (Table 2).

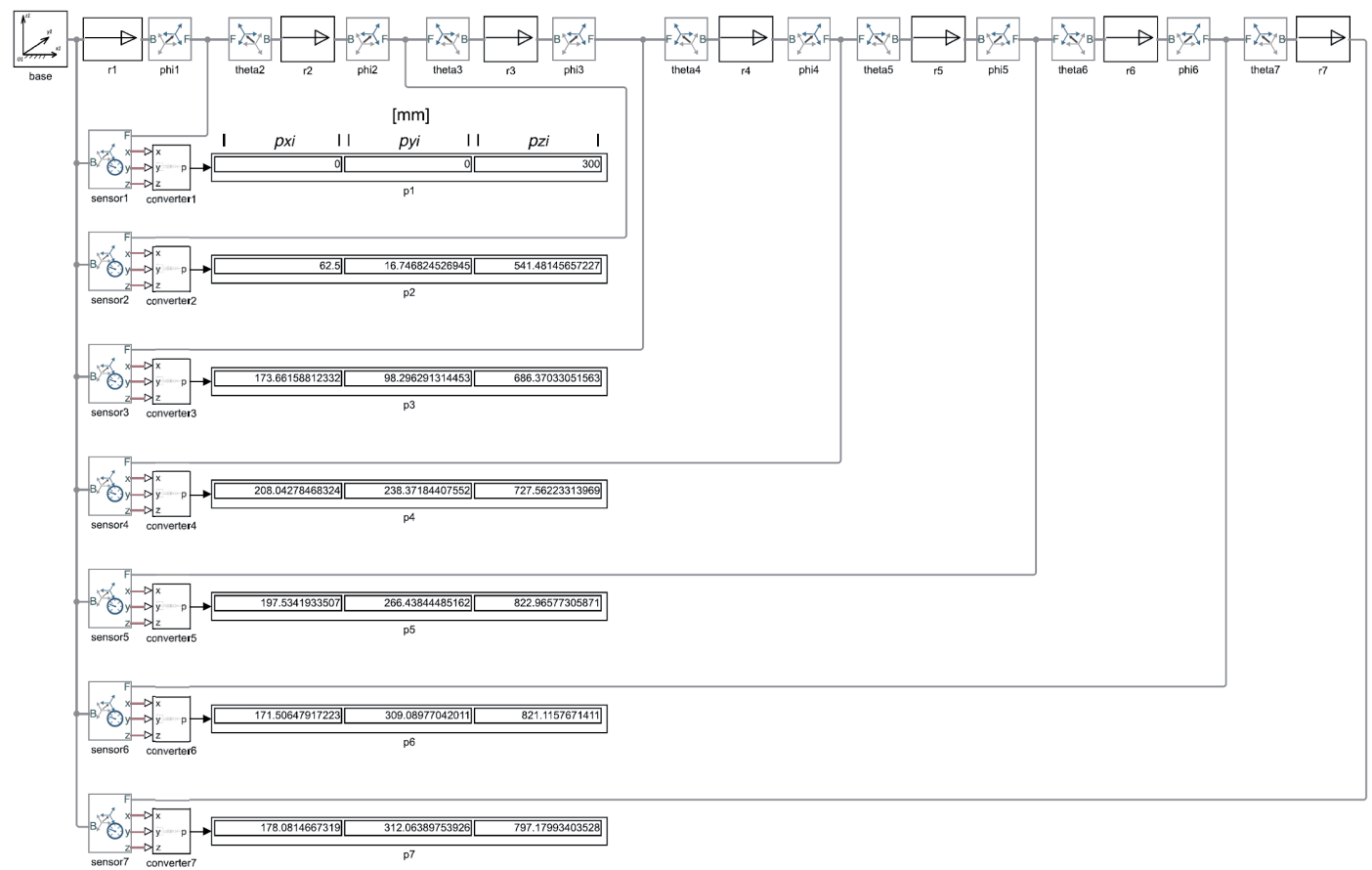

Figure 3: Mechanical model of the robotic arm with mounted position sensors.

Table 2: Components of the position vectors pi derived from the parameters (Table 1) inserted into individual models (Figure 2), (Figure 3).

\begin{tabular}{|c|c|c|c|c|c|c|}
\hline \multirow{2}{*}{$\begin{array}{l}\text { Position } \\
\text { vector }\end{array}$} & \multicolumn{3}{|c|}{ Results from mathematical model (Figure 2) } & \multicolumn{3}{|c|}{ Results from mechanical model (Figure 3) } \\
\hline & $\begin{array}{l}\text { vector component - } \\
\boldsymbol{p}_{\mathrm{x}} \\
{[\mathrm{mm}]}\end{array}$ & $\begin{array}{l}\text { vector component - } \\
\boldsymbol{p}_{\mathrm{y}} \\
{[\mathrm{mm}]}\end{array}$ & $\begin{array}{l}\text { vector component - } \\
\boldsymbol{p}_{\mathrm{z}} \\
{[\mathrm{mm}]}\end{array}$ & $\begin{array}{l}\text { vector component - } \\
\boldsymbol{p}_{\mathrm{x}} \\
{[\mathrm{mm}]}\end{array}$ & $\begin{array}{l}\text { vector component - } \\
\boldsymbol{p}_{\mathrm{y}} \\
{[\mathrm{mm}]}\end{array}$ & $\begin{array}{l}\text { vector component - } \\
\boldsymbol{p}_{\mathrm{z}} \\
{[\mathrm{mm}]}\end{array}$ \\
\hline$p_{1}$ & 0 & 0 & 300 & 0 & 0 & 300 \\
\hline$p_{2}$ & 62.5000 & 16.7468 & 541.4814 & 62.5000 & 16.7468 & 541.4814 \\
\hline$p_{3}$ & 173.6615 & 98.2962 & 686.3703 & 173.6615 & 98.2962 & 686.3703 \\
\hline$p_{4}$ & 208.0427 & 238.3718 & 727.5622 & 208.0427 & 238.3718 & 727.5622 \\
\hline$p_{5}$ & 197.5341 & 266.4384 & 822.9657 & 197.5341 & 266.4384 & 822.9657 \\
\hline$p_{6}$ & 171.5064 & 309.0897 & 821.1157 & 171.5064 & 309.0897 & 821.1157 \\
\hline$p_{7}$ & 178.0814 & 312.0638 & 797.1799 & 178.0814 & 312.0638 & 797.1799 \\
\hline
\end{tabular}




\section{Results and Discussion}

The mechanical model confirmed the correctness of the calculation and the data are practically identical. An undisputed advantage of virtual models is the exactness of their calculations, unachievable through real measurement taking. Therefore, the values for both models have been entered into one table only (Table 2). The next picture (Figure 4) shows a structure generated according to the model by the above-mentioned program

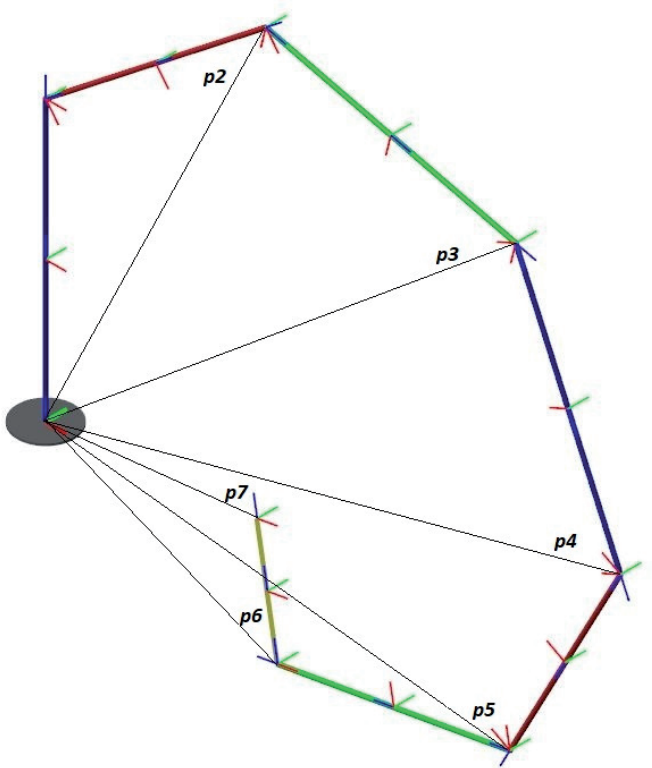

environment (Figure 3). Both models (mathematical, mechanical) will continue to be tested, subject to various applicability scenarios for the arm made of the URM modules. One of the issues is, for example, a search for an optimum angle $\boldsymbol{\vartheta}_{\mathrm{i}}$ and its impact on the size of the workspace. Any search for an optimum must stem from requirements defined for the structure at hand. Thus, defining an optimum for any of the $\boldsymbol{\vartheta}_{\mathrm{i}}, \boldsymbol{r}_{\mathrm{i}}$ parameters will depend mostly on practical requirements.

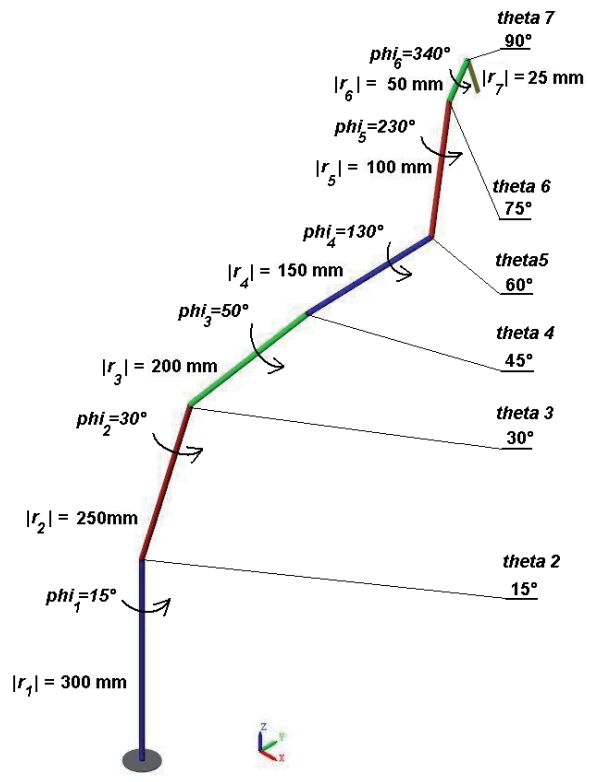

Figure 4: Mechanical model of the robotic arm showing position vectors.

\section{Acknowledgments}

This paper has been prepared with the support of the following grant projects: KEGA 025TUKE-4/2019 Integrated teaching laboratory of virtual prototyping and experimental verification of the machine tools accuracy; APVV-18-0413 Modular architecture of the manufacturing technology structural elements.

\section{References and Notes}

[1] Jozef Svetlík, Modularity of Production Systems, DOI: 10.5772/intechopen.90844, February 13th 2020

[2] John K. Gershenson, Assistant Professor G. Jagannath Prasad, Graduate Research Associate, Modularity in product design for manufacturability, Department of Mechanical Engineering The University of Alabama, International Journal of Agile Manufacturing, Volume 1, Issue 1, August, 1997

[3] Hichem Haddou Benderbal, Mohammed Dahane, Lyes Benyoucef, Modularity assessment in reconfigurable manufacturingsystem (RMS) design: an Archived MultiObjective Simulated Annealing-based approach, SpringerVerlag London Ltd. 2017

[4] Roberto Pérez R., Joaquín Aca S., Andrés Valverde T., Horacio Ahuett G., Arturo Molina G., Carles Riba R., A Modularity Framework for Concurrent Design of Reconfigurable Machine Tools, Cooperative Design, Visualization, and Engineering, 2004, Volume 3190, ISBN : 978-3-540-23149-3

[5] Nicolay Worren, Karl Moore, Pablo Cardona, Modularity, Strategic flexibility, and firm performance: A study of the home appliance industry, Strategic Management Journal 2002

[6] Jozef Svetlik, Miroslav Štofa, Martin Pituk, Prototype development of a unique serial kinematic structure of modular configuration, MM Science Journal 2016 (2016): 994-998.

[7] Štofa, M., and J. Svetlík. " Development of the second generation URM 02." современные концепции развития науки. 201 
[8] Sciavicco, Lorenzo, and Bruno Siciliano, Modelling and control of robot manipulators, Springer Science \& Business Media, 2012.

[9] Khalil, Wisama, and Etienne Dombre, Modeling, identification and control of robots, ButterworthHeinemann, 2004.

[10] Švejda, Martin. ,TAČR Centrum kompetence CIDAM Survey: Existing methods and tools for optimization of mechatronic systems in terms of structure, parameters and control, (2015).

[11] Murray, Richard M., et al., A mathematical introduction to robotic manipulation, CRC press, 1994.

[12] Nicolescu, Adrian-Florin, Florentin-Marian Ilie, and TudorGeorge Alexandru, Forward and inverse kinematics study of industrial robots taking into account constructive and functional parameter's modeling, Proceedings in Manufacturing Systems 10.4 (2015): 157.

[13] Crane III, Carl D., and Joseph Duffy, Kinematic analysis of robot manipulators, Cambridge university press, 2008

[14] Guida, R., et al. ,Modeling techniques for kinematic analysis of a six-axis robotic arm, IOP Conference Series: Materials Science and Engineering. Vol. 568. No. 1. IOP Publishing, 2019

[15] Ondočko Š., Stejskal T., Svetlík J., Šašala M., hrivniak L., Priama kinematika modulárneho systému, ARTEP2020Automatizácia a riadenie $v$ teórii a praxi, TUKE, 2020

[16] Svetlík J., Príspevok k stavbe výrobnej techniky na princípoch pružnej architektúry, Habilitačná práca, Košice: TU, 2012.

[17] Štofa M., Experimentálny vývoj rotačných modulov pre stavbu sériových kinematických štruktúr vo výrobnej technike, Dizertačná práca, Košice: TU, 2019.

[18] Robert G., Kinematika a dynamika mechatronických systému, Vysoké učení technické v Brňe, Brno , 2007

[19] Smutný V., Robotika, České vysoké učení technické v Praze, Praha 2019

[20] Euklidovský priestor E3, http://www.evlm.stuba. sk/ velichova/Geometria/Prednasky/predB1.htm

[21] Matlab - MathWorks - Matlab \& Simulink, Matlab Documentation, https://uk.mathworks.com/help/matlab/ ref/help.html, 2018.

[22] Geometry with Trigonometry (Second Edition), 2016, https://www.sciencedirect.com/topics/mathematics/ position-vector

[23] Göhler W., Ralle B., Lexikón vyššej matematiky, VEB Deutscher Verlag für Grundstoffindustrie, Leipzig, 1987

[24] https://whatis.techtarget.com/definition/end-effector

[25] https://blog.robotiq.com/bid/53266/Robot-End-EffectorDefinition-and-Examples

[26] http://www.electronicsteacher.com/robotics/roboticstechnology/effectors.php

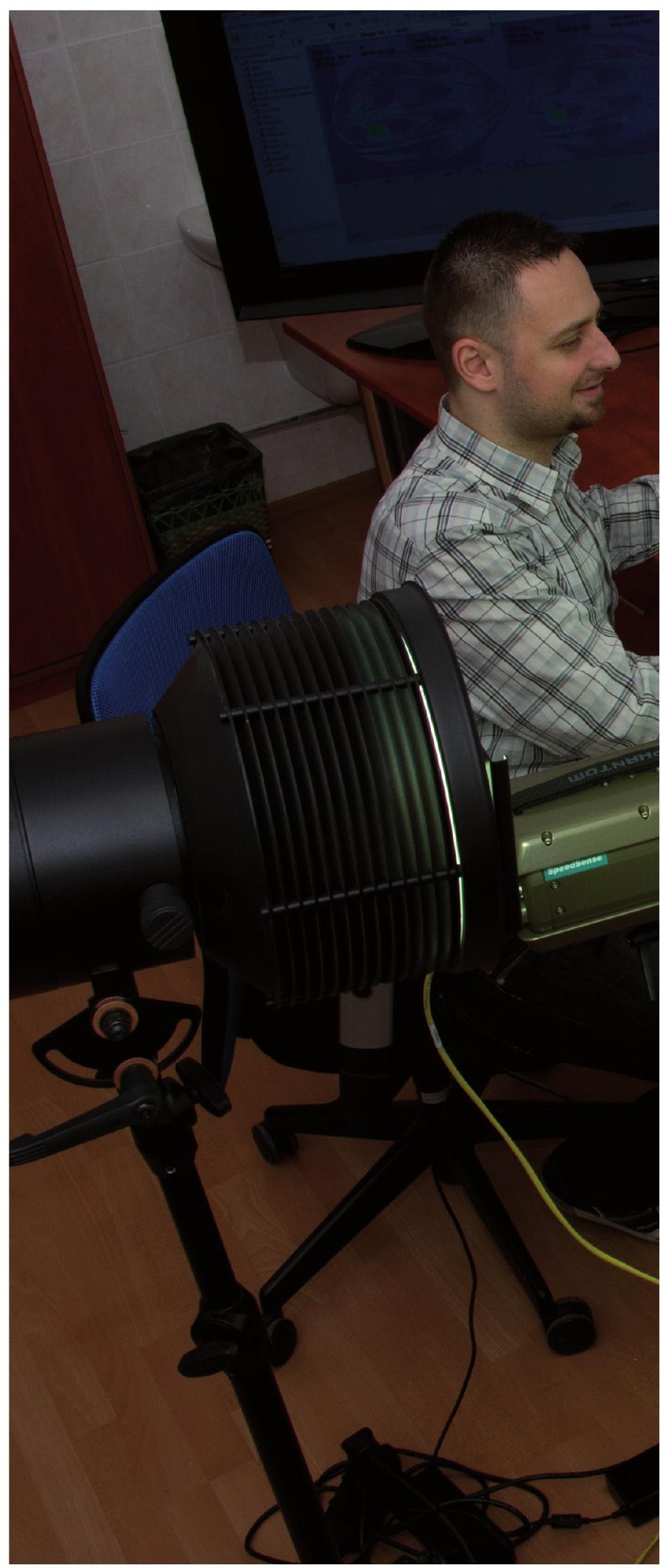

